IEEE Instrumentation and Measurement

Technology Conference

Ottawa, Canada, May 19-21, 1997

\title{
Instrumentation System to Implement LEAK TEST PROGRAM
}

\author{
W.J. Turner, Ryan Brown, and David Rael \\ Los Alamos National Laboratory \\ Box 1663 MS E583 \\ Los Alamos, NM 87545 \\ Phone (505) 667-2648 Fax (505) 667-7193
}

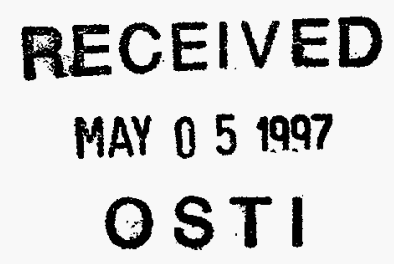

\begin{abstract}
HVAC equipment, gloveboxes, and other types of enclosures are required to meet rigid welldefined leak rates when they are to be installed in a nuclear facility. This paper describes two implementations of an instrumentation system that is used to test leak rates on heating, ventilation, and air conditioning (HVAC) plenums, gloveboxes, and experimental chambers, etc. One of the implementations used a programmable logic controller (PLC). The other used what is probably a simpler system based on FlexNeto modules. The emphasis on both systerns was on automatic data collection, automatic report generation, and validation of the test results to ERDA 76-21 and ASME-N510. The data are collected using input modules connected to the PLC in one case. In the other case the data are collected using the FlexNeto modules. In both cases, the data are stored and the reports are generated in a spreadsheet.
\end{abstract}

\section{INTRODUCTION}

Los Alamos National Laboratory is located in northern New Mexico. The only operational plutonium facility in the United States is located at this laboratory. As a nuclear facility, the operations are performed under stringent requirements from the Department of Energy DOE), the Defense Nuclear Facility Safety Board (DNFSB) and other regulatory bodies. One of the main thrusts of the requirements is to ensure safety of the public and the workers.

A requirement that comes up often is to test various enclosures for leaks. These tests have typically been performed by using meters (pressure and temperature and a stopwatch) and by recording the information in a log book or data sheet. This report presents two implementations of a small instrumentation system that will automate the measurement process and standardize the calculations and presentation of the results.

\section{THEORY}

The leak rate is calculated from the following equation that is extracted from [1].

$$
Q=\left[\left(P_{i} / T_{i}-P_{f} / T_{f}\right) \bigvee /[R \Delta t(0.075)]\right.
$$

where

$Q=$ average leak rate, SCFM

$V=$ volume within test boundary, $\mathrm{ft}^{3}$

$P_{i}=$ initial pressure within test boundary $\mathrm{lb} / \mathrm{ft}^{2} \mathrm{ABS}$

$P_{f}=$ final pressure within test boundary $\mathrm{lb} / \mathrm{ft}^{2} \mathrm{ABS}$

$T_{i}=$ initial temperature within test boundary ${ }^{\circ} \mathrm{R}$

$T_{f}=$ final temperature within test boundary ${ }^{\circ} R$

$\Delta t=t_{f}-t_{j}$

$t_{i}=$ time at start of test, $\min$

$t_{f}=$ time at end of test, $\min$

$R=$ gas content for air $=53.35 \mathrm{ft} \mathrm{lb} / \mathrm{bb}{ }^{\circ} \mathrm{R}$.

This equation shows that the pressure, temperature, and time must be measured to determine the leak rate. In addition, the volume of the test enclosure must be either calculated or measured.

\section{EXPERIMENTAL SETUP}

\section{A. Hardware}

1) Volume Under Test:Three different items have been leak-tested to date with the systems described here. Two of the items were HVAC plenums (Fig. 1), and the other was a room that spanned two stories in the facility. In the 


\section{DISCLAIMER}

This report was prepared as an account of work sponsored by an agency of the United States Government. Neither the United States Government nor any agency thereof, nor any of their employees, make any warranty, express or implied, or assumes any legal liability or responsibility for the accuracy, completeness, or usefulness of any information, apparatus, product, or process disclosed, or represents that its use would not infringe privately owned rights. Reference herein to any specific commercial product, process, or service by trade name, trademark, manufacturer, or otherwise does not necessarily constitute or imply its endorsement, recommendation, or favoring by the United States Government or any agency thereof. The views and opinions of authors expressed herein do not necessarily state or reflect those of the United States Government or any agency thereof. 


\section{DISCLAIMER}

Portions of this document may be illegible in electronic image products. Images are produced from the best available original document. 


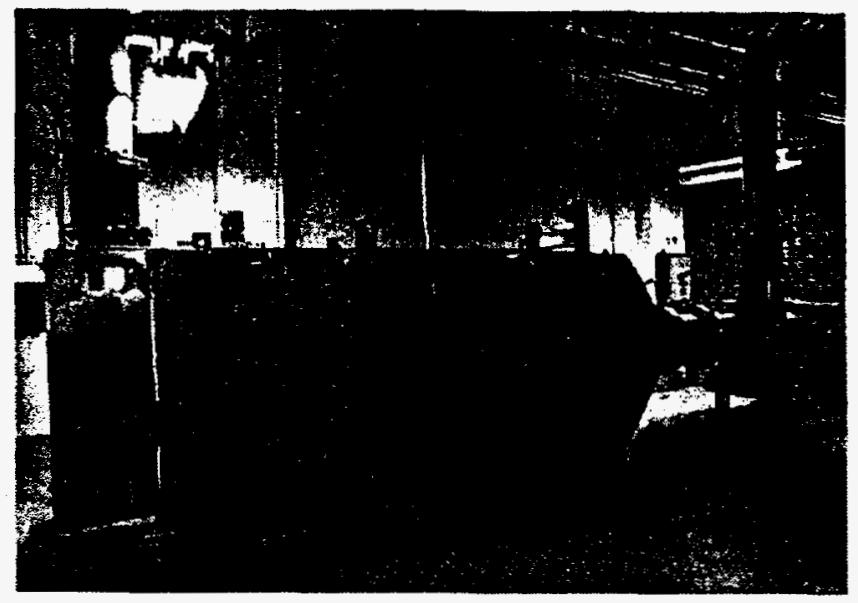

Fig. 1. HVAC Plenum.

future we plan to use this process to measure leaks in gloveboxes (Fig. 2). The important factor here is that the measurement system must go to the volume and not the volume to the measurement device.

Fittings are installed in the envelope of the volume for attaching the sensors and the vacuum or pressure equipment. Usually a compression fitting is used for installing a resistance temperature device (RTD) or a thermocouple. Hose barbs are usually installed for attaching the pressure sensors and the pumps used for pressurizing or evacuating the volume.

2) Programmable Logic Controller (PLC) System: The programmable logic controller (PLC) system (Fig. 3) consists of a PLC, power supply, analog input module, and a discrete input switch module. The discrete input switch module is used to switch between the different functions in the ladder logic program. Inputs come from pressure and temperature sensors. In this system, ladder logic in the PLC is used to set the sample rate and

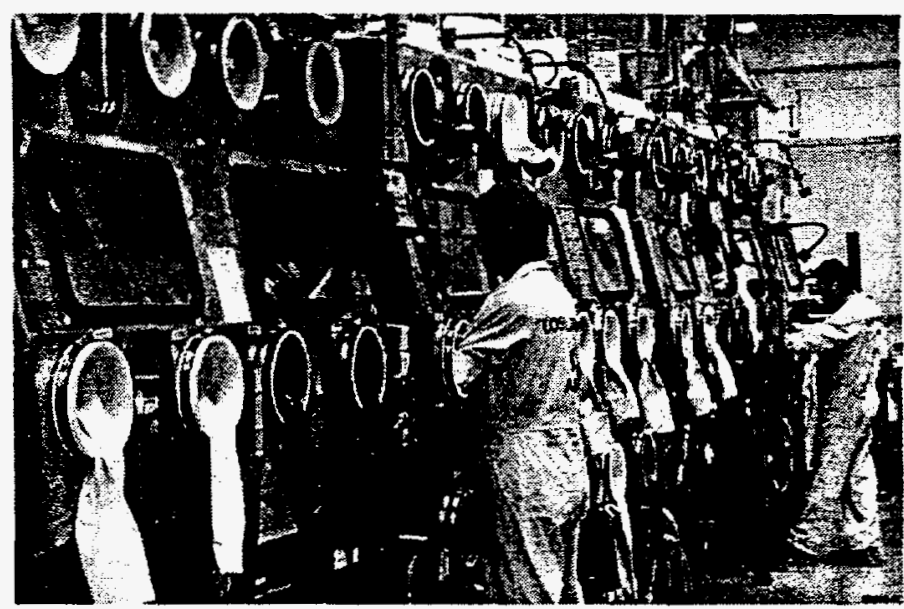

Fig. 2. Glovebox.

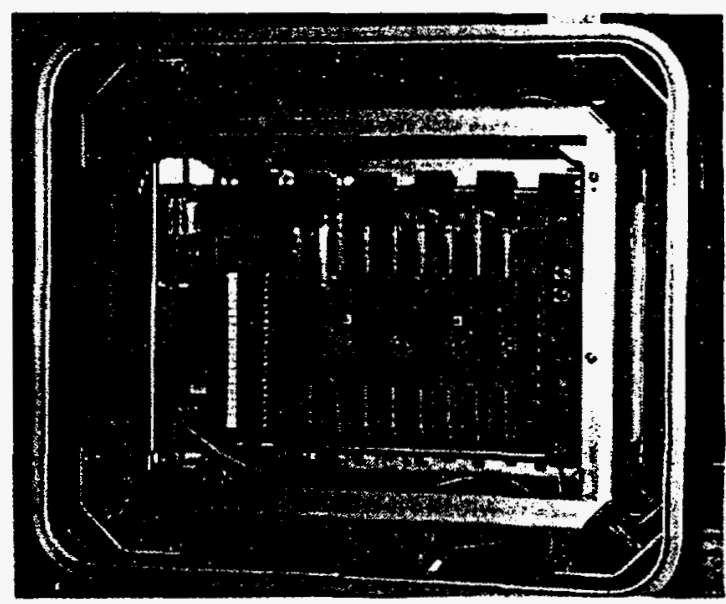

Fig. 3. PLC System.

the experimental parameters. The data and calculations are linked to a spreadsheet with a dynamic data exchange (DDE) link.

3) FleXnet@ System:This system (Fig. 4) performs the same functions as the previous one. The differences are in the link between the sensors and the spreadsheet. The modules have a much slower response than the PLC but are still appropriate for this task. The main difference is in the size of the system. The Flexnetco hardware is very lightweight and can therefore be more easily carried to the test location.

\section{B. Software}

1) PLC System: As mentioned earlier, the functionality of the PLC system is mostly contained in the ladder logic (see [2]) in the PLC. The calculations are all performed and the conduct of the experiment is managed by using the ladder logic. For instance, when performing a leak test using the pressure decay method, it is required that

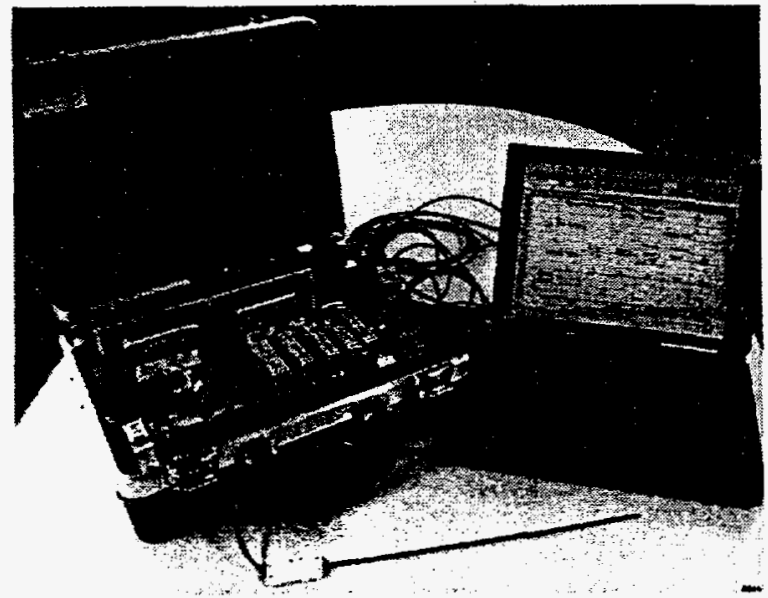

Fig. 4. The FleXnet System. 
data be collected between two pressures. If the enclosure is tight, the test can be terminated early before decaying to the second pressure. It is not required that any data be saved while the volume is being pressurized. In the PLC, these details are done manually by changing the positions of the switches on the discrete switch input module. The ladder logic looks for a change in switch position to enable data collection.

2) FleXneto System: The FleXnet( system performs the same function as the PLC system, but in this case the programming is contained in the spreadsheet using visual basic for applications (VBA); (see [3]). This software is configured so that the data collection is enabled by using the mouse to check a box on the spreadsheet instead of looking for a switch change-of-state as in the PLC system.

\section{CONCLUSIONS}

Two different approaches to data collection have been presented. Both can use the same sensors, and data from both of them can be placed in the same format in a spreadsheet. The spreadsheet shown has columns for two pressure sensors and two temperature sensors.
Although data is only shown for one pressure sensor and one temperature sensor, the other columns are available so that the two sensors can be used and averaged for more reliable and accurate data.A copy of the spreadsheet is shown in the appendix. Both approaches are designed to collect data and compute a leak rate based on the pressure decay method. Any other application that the reader might envision could be implemented easily. When the method of reporting is decided, the instrumentation can be upgraded without making changes to the report.

\section{ACKNOWLEDGMENTS}

We would like to thank Mable Amador for her editing assistance, Mick Greenbank for his photography, and Rob Davis for his drafting support.

\section{REFERENCES}

[1] "Leak test program for ductwork for 7 inch impact tester - HVAC PF4, TA55," prepared by Johnson Controls Inc., unpublished.

[2] PLC-5 Programming Software Release 4.4 Instruction Set Reference, Milwaukee, Wi: Allen Bradley Company Inc., 1993.

[3] Microsoft Excelvisual Basic Programmer's Guide, Redmond, WA Microsoft Press, 1995. 


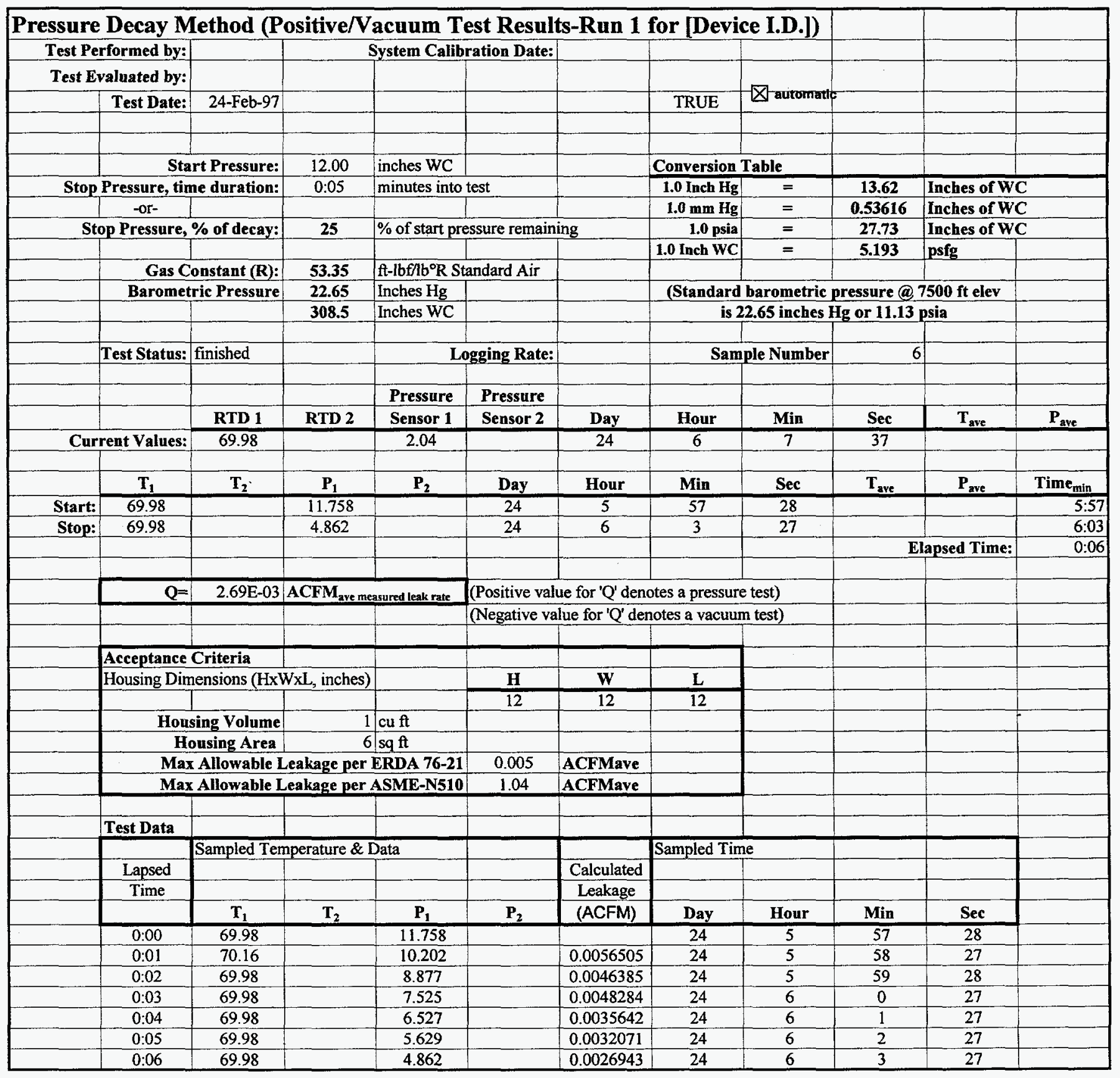

